\title{
As políticas públicas para a agricultura familiar brasileira em clima semiárido: do combate à convivência
}

\section{The public policies for Brazilian family farming in semiarid climate: from drought combat to daily living in such climate}

\section{Las políticas públicas para la agricultura familiar brasileña en clima semiárido: del combate a la convivencia}

Daniel Alves Campelo, mestre em Gestão do Desenvolvimento Local Sustentável pela Faculdade de Ciências da Administração de Pernambuco da Universidade de Pernambuco (FCAP/UPE). Endereço: Rua Major Armando de Souza Melo, 42, apto 702B Boa Viagem. CEP: 51030-180 - Recife, PE. Telefone: (81) 92964261/ 3301-1355. E-mail: danicampelo@gmail.com.

\section{Resumo}

O trabalho apresenta as políticas públicas direcionadas para as famílias agricultoras, fundamentalmente aquelas que vivem em regiões de clima semiárido, tendo como objetivo geral apresentar as ideologias das políticas públicas de combate à seca, realizadas no início do século XX, comparando-as com as políticas de convivência com o clima semiárido, que trazem uma nova configuração de estratégia para a sustentabilidade do desenvolvimento local. Para tanto, apresentouse a importância das políticas públicas para a pequena agricultura e promoção do desenvolvimento sustentável, tendo como cenário principal o ciclo das secas, no período compreendido entre 1900 e 1970, bem como as mudanças de paradigmas nos modelos de produção da agricultura familiar, desde os modelos convencionais, transitando pelo período que ficou conhecido como revolução verde, até a agroecologia.

Palavras-chave: Políticas Públicas. Agricultura Familiar. Semiárido. 


\section{Abstract}

This work presents the public policies that focus on family agriculture, particularly on that undertaken in the semiarid region. The objective of the article is to analyze the public policy ideologies undergirding the 'battle against the drought' of the early XX century and compare them to the coexistence policies of the semiarid climate that represent a new strategy for local sustainable development. Therefore, the importance of the public policies during the drought cycle between 1900 to 1970 for small-scale agriculture and the promotion of sustainable development are presented. Also discussed are the paradigm changes that occurred in the models of family agriculture production, considering both conventional models and those adopted throughout the period of the so-called green revolution and agroecology.

Keywords: Public Policies. Family Agriculture. Semiarid.

\section{Resumen}

El trabajo presenta las políticas públicas dirigidas a la agricultura familiar, fundamentalmente aquellas que viven en regiones de clima semiárido, con el objetivo general de presentar las ideologías de las políticas públicas de combate a la sequía, celebradas a principios del siglo XX, comparándolas con las políticas de convivencia con el clima semiárido, que traen una nueva configuración de estrategia para la sostenibilidad del desarrollo local. Para ello, se mostró la importancia de las políticas públicas para la agricultura en pequeña escala y la promoción del desarrollo sostenible, teniendo como escenario principal el ciclo de las sequías, en el periodo comprendido entre 1900 y 1970, así como los cambios de paradigmas en los modelos de producción de la agricultura familiar, desde los modelos convencionales, en el periodo que se conoció como la revolución verde, hasta la agroecología.

Palabras clave: Políticas Públicas. Agricultura Familiar. Semiárido. 


\section{Introdução}

Com o intuito de aprofundar a discussão sobre a importância da agricultura familiar, das políticas públicas para a promoção do desenvolvimento sustentável na região semiárida e do acesso a essas políticas por parte dos agricultores familiares, este trabalho visa mostrar a importância da agricultura familiar na produção agrícola nacional, quais são as principais políticas existentes para esses agricultores e a mudança de paradigma nas políticas públicas para os agricultores familiares na região semiárida.

Para tanto, observou-se o papel da agricultura familiar na produção agrícola e do Estado, tendo como fundamento as políticas públicas voltadas para agricultura familiar em regiões de clima semiárido que estejam em acordo com a realidade local, identificando sua importância e a evolução histórica dessas políticas.

Para efetivar o objetivo proposto, em um primeiro momento, apresenta-se a importância da agricultura familiar para a produção agrícola nacional. Em seguida, destaca-se a importância das políticas públicas para a agricultura familiar e apontam-se quais são essas políticas, levando em conta que um dos grandes desafios é identificálas. Após admitir a existência dessas políticas direcionadas para as famílias agricultoras, chama-se a atenção para a relevância delas e também se comenta o acesso por parte das famílias agricultoras.

Em seguida, o trabalho faz uma abordagem histórica dos ciclos da seca e das políticas existentes de combate à seca; por fim, aborda a mudança de paradigma e a transição para a agroecologia, apontando para uma nova ideologia de convivência com o clima semiárido.

Em função dessas transformações conceituais, acreditamos que o resultado deste trabalho se torna relevante ao apresentar para sociedade a importância de sua participação. Pois, considerando a atuação efetiva do Estado com ações específicas para a agricultura familiar, é preciso que a sociedade se aproprie dessas informações e sirva como um catalisador, para que as políticas cheguem efetivamente às famílias agricultoras. 
Nas considerações finais, aborda-se a percepção de que ainda não há uma estratégia que seja um modelo para solucionar o problema da agricultura familiar. Destaca-se, nesse processo, a importância da participação do Estado na promoção do desenvolvimento sustentável da agricultura familiar, por meio de políticas de fomento à população rural, e ainda o fato de que as ideologias, baseadas em estratégias de governo, vão se modificando, buscando atender a complexidade da região semiárida, apresentando uma crescente e sustentada evolução das políticas públicas para a agricultura familiar.

\section{A importância da agricultura familiar e das políticas públicas}

A agricultura familiar tem relevante papel na produção agrícola brasileira. Segundo o Censo Agropecuário 2006 (IBGE, 2006), a agricultura familiar, em algumas culturas, é responsável por mais da metade da produção nacional brasileira, como é o caso da mandioca, com $87 \%$ da produção nacional; do feijão, em que a agricultura familiar é responsável por $70 \%$ da produção nacional; e leite, com 58\% da produção nacional. Merece destaque ainda o milho, com 46\%; e o café, com 38\%. Na pecuária, a agricultura familiar também tem importância significativa. Ainda de acordo com o Censo Agropecuário 2006, a agricultura familiar detém 59\% do plantel de suínos, 50\% do plantel de aves e 30\% dos bovinos.

Dados esses relevantes aspectos, é preciso atenção para a

Para este trabalho, consideraram-se as definições de agricultura familiar tal qual o critério adotado em um estudo realizado pela FAO/Incra (2000), que chamou de agricultura familiar basicamente os estabelecimentos em que a direção dos trabalhos era exercida pelos produtores e o trabalho familiar era superior ao contratado As duas características deveriam ser atendidas simultaneamente. discussão das perspectivas estruturais do Estado, que seria, junto com as grandes empresas, o único promotor do desenvolvimento, apresentando notadamente um fortalecimento da atividade econômica local. Isso garantiria à agricultura familiar ${ }^{1}$ fundamental importância na produção agrícola nacional. Nota-se, nesse breve contexto, a importância do poder público e de sua relação com a sociedade civil (MOURA, 1998).

De acordo com Teixeira (2002), as políticas públicas traduzem a forma de exercer poder político, e, como o poder é uma relação social que envolve vários atores, são necessárias, para que as 
políticas públicas sejam legítimas e eficazes, mediações sociais e institucionais.

Diante da necessidade de promoção e regulação dos aspectos referentes às relações socioeconômicas, para combater o desequilíbrio imposto pelo capitalismo, as políticas públicas devem investir em áreas estratégicas, capazes de promover o desenvolvimento econômico e o bem estar social (TEIXEIRA, 2002).

De acordo com Toledo (2002), com a separação entre o Estado e a economia e, ainda, com a tentativa de despolitizar as relações econômicas e sociais, o liberalismo, movimento social que predominou até a década de 1970, entra em decadência. A partir daí, ganhou espaço o neoliberalismo.

Teixeira (2002, p. 4) observa nesse período a falência do Estado protetor e ainda o agravamento da crise social. O neoliberalismo propõe uma reformulação estrutural nas políticas públicas, a redução dos gastos sociais, pois responsabiliza a política do intervencionismo como principal responsável pelo estagnacionismo. O autor afirma sobre as políticas públicas:

A globalização torna o processo de formulação de políticas públicas mais complexo, por estarem em jogo, agora, em cada país, interesses internacionais representados por forças sociais com um forte poder de interferência nas decisões quando essas não são diretamente ditadas por organismos multilaterais.

A partir daí, dado o elo entre sociedade e Estado, como promotor das políticas públicas, observou-se que o pensamento único neoliberal, reforçado pela necessidade de ajustar as políticas, no final da década de 70, principalmente aquelas criadas pelo esgotamento da fase chamada substituição de importações, atropelou o crescimento com equidade (SANTOS, 2007).

Com o avanço do neoliberalismo no Brasil e no mundo, o socialismo havia sido colocado como uma forma de organização da sociedade cada vez mais sem futuro e perspectiva. Esse cenário 
indicava o avanço da globalização, a partir da lógica da subordinação da agricultura ao capital financeiro e industrial (MOURA, 2011).

Porém, aponta Santos (2007), o início da década de 80 indica um descenso dessa ortodoxia neoliberal. Nesse processo de mudança na relação do Estado com a sociedade, as políticas púbicas voltadas para a agricultura familiar passaram também por diversas transformações conceituais, incluindo, nos dias atuais, a participação da sociedade na formação dessas políticas.

No Brasil, as políticas formuladas para a agricultura familiar foram de ordem agrícola ou agrária. Denardi (2001) destaca que as políticas agrárias foram quase inexistentes no Brasil.

Já as políticas agrícolas foram, de fato, as políticas públicas voltadas para a agricultura, incluindo a produção familiar, nas últimas quatro décadas. Teixeira (2002, p. 10), fundamentado na Lei de Política Agrícola ( $n^{\circ} 8.171$, de 17.01.91), define a política agrícola da seguinte forma:

[...] do ponto de vista formal, define os princípios fundamentais, objetivos e competências institucionais, prevê recursos, estabelece ações e instrumentos. A lei enfatiza a questão econômica (produtividade, incremento à produção, regularidade de abastecimento), enquanto a Constituição tem por referência a função social da propriedade. Equiparar estas duas dimensões, em nossa estrutura agrária, significa uma opção pelo produtivismo e pela tecnificação, independente de seus impactos sociais e ambientais.

São às políticas agrícolas que a agricultura familiar está submetida. De acordo com o Censo Agropecuário 2006 (IBGE, 2006), no Brasil, $84,4 \%$ dos estabelecimentos são familiares, responsáveis por 38\% do Valor Bruto da Produção (VBP). Embora tenham grande participação na produção nacional, esses agricultores familiares ocupam apenas uma área de 80,25 milhões de hectares, ou seja, 24,3\% da área ocupada pelos estabelecimentos agropecuários brasileiros.

Isso reforça a importância da agricultura familiar brasileira e a necessidade de políticas que promovam o desenvolvimento da 
agricultura familiar e a melhoria na qualidade de vida da população rural, sem descartar a importância da preservação do meio ambiente.

No que concerne às políticas agrícolas, apresentam-se alguns avanços, principalmente graças à luta dos trabalhadores rurais. Porém, para realizar a reforma agrária de forma justa e eficiente, ainda persistem obstáculos burocráticos, jurídicos, econômicos, políticos e, inclusive, constitucionais (TEIXEIRA, 2002).

A reforma agrária não deve limitar-se apenas a dar terra para quem não a tem, mas, além disso, a aumentar a propriedade dos agricultores familiares de pequenas propriedades, que, devido à falta de espaço para a gestão da terra, promovem práticas agrícolas que causam impactos negativos no meio ambiente (PÁDUA, 2004).

Outro grande problema, como alerta Teixeira (2002), é que o trabalho escravo ainda é uma realidade; além disso, não há desapropriação de pequenas e médias propriedades para a distribuição de terras. A função social da propriedade é definida muito mais em termos econômicos do que em termos sociais e ambientais, que são tratados de maneira superficial.

Merecem atenção especial essas áreas de pequenas propriedades, cuja produção agrícola é de base familiar e, em grande parte, estão situadas em região de clima semiárido (além das dificuldades já encontradas pela agricultura familiar, ainda encontra no clima um grande opositor).

Sendo o clima um fator fundamental para a produção agrícola, desenvolver a agricultura com alimentos de qualidade, resultando em uma melhora na saúde da população e na expansão da biodiversidade, é um aspecto que deve ser considerado. Diante do cenário apresentado do meio rural e das políticas públicas desenvolvidas, tanto no âmbito nacional, quanto no local, é inegável que é preciso pensar a agricultura familiar em uma perspectiva sustentável.

O desenvolvimento sustentável ${ }^{2}$ na agricultura depende sobremaneira das práticas adotadas pelos agricultores, principalmente,

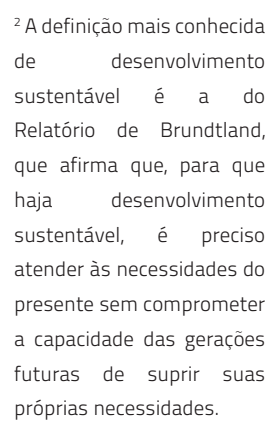
a capacidade das gerações futuras de suprir suas próprias necessidades. 
das práticas utilizadas pelos agricultores familiares, uma vez observada sua importância para a produção nacional. Os altos rendimentos e a lucratividade têm impulsionado a inovação na agricultura nos últimos 40 ou 50 anos, porém uma série de efeitos colaterais ambientalmente negativos tem-se apresentado (GLIESSMAN, 2000).

Ainda de acordo com Gliessman (2000), nos primeiros um ou dois anos de transição, os produtores apresentam uma redução de rendimento e lucro; no entanto, a maioria daqueles que persistem acabam tendo, devido à conversão, benefícios econômicos e ecológicos. Nessa perspectiva, diversos fatores estão encorajando os produtores para a conversão: custo crescente da energia, baixa margem de lucro das práticas convencionais, desenvolvimento de novas práticas como opção viável, aumento da consciência ambiental e novos e mais consistentes mercados cultivados e processados de forma alternativa.

Nessa perspectiva de sustentabilidade na agricultura, segundo Altieri (2012), há cinco pontos que explicam a importância da agricultura familiar para o desenvolvimento sustentável: a pequena produção é a chave para a segurança alimentar mundial, pois terá muito mais impacto na disponibilidade de alimentos em nível local; é mais produtiva, pois conserva mais os recursos naturais do que a monocultura; propriedades diversificadas representam modelo de sustentabilidade; ela representa um santuário de agrobiodiversidade, livre de Organismos Geneticamente Modificados (OGMs); e as pequenas propriedades rurais resfriam o clima (menos emissão de gases de efeito estufa).

Diante dessa preocupação com a promoção de uma agricultura preocupada com os aspectos ambientais, hoje as políticas públicas voltadas para a agricultura familiar em clima semiárido têm como princípio a convivência com o clima semiárido, mas não foi sempre assim. Sobre essa nova concepção de promover política em clima semiárido, trataremos mais adiante. A verdade é que as primeiras políticas promovidas pelo governo federal voltadas para a agricultura familiar eram conhecidas como políticas de combate à seca. 
É nessa relação do Estado com a sociedade e a economia, com tanta desigualdade e discrepantes ideologias políticas, que a agricultura de base familiar se consolidou em áreas de clima semiárido, em condição de pobreza e necessidade de políticas públicas de fomento. Observam-se a seguir as principais políticas públicas voltadas para a agricultura familiar, no período que compreende o início do século passado até os dias atuais.

\section{Os ciclos da seca no semiárido e as políticas de combate à seca}

No Brasil, segundo o Programa das Nações Unidas para o Desenvolvimento (Pnud) ${ }^{3}$, milhões de pessoas enfrentam um problema crônico de falta de água, vivendo no chamado polígono das secas. De acordo com o relatório final do estudo realizado pelo Grupo de Trabalho Interministerial (GTI), divulgado pelo Ministério da Integração Nacional, o semiárido é formado por 1.133 municípios, em uma área total de 969.589,4 km² (BRASIL, 2005).

Nessa região, de tempos em tempos, as grandes estiagens agravaram as dificuldades já encontradas pela população, deixando-a, principalmente nesse período, mais dependente das intervenções do Estado, sobretudo das políticas que atenuassem a difícil condição imposta pelo clima e que fossem capazes de promover alternativas de emprego e renda para a agricultura familiar.

No período que se estende de 1915 até o início dos anos 2000, a região do polígono das secas enfrentou oito períodos de secas bastante marcantes. Porém, antes desse período, ainda no final do século XIX, as secas passaram a ser vistas como um problema importante para 0 governo brasileiro. As primeiras ações realizadas com a perspectiva de atenuar o impacto dos períodos secos foram as construções do açude do Cedro, no Ceará, e do açude de Poços, na Paraíba (VILAR FILHO, 2001).

Para Batista Filho (2001 apud CAMPELO; HAMASAKI, 2011), era necessário eliminar a indústria da seca, mas isso só seria

${ }^{3}$ Por definição, o Programa das Nações Unidas para o Desenvolvimento (Pnud) é a rede de desenvolvimento global da Organização das Nações Unidas. 0 Pnud faz parcerias com pessoas em todas as instâncias da sociedade para ajudar na construção de nações que possam resistir a crises, sustentando e conduzindo um crescimento capaz de melhorar a qualidade de vida para todos. 
possivel se fossem contornadas as limitações existentes, realizando transformações de ordem social e melhorando a qualidade de vida da população; além disso, era necessário que fosse feita uma reforma agrária que garantisse uma maior proporção de renda produzida na agricultura e pecuária ao produtor rural.

O que se observou, como se apresenta a seguir, é que as políticas públicas acompanharam os ciclos da seca, obedecendo inicialmente à ideologia de combate à seca, remetendo à ideia de transclimação, supondo-se a condição de mudar o clima (VILAR FILHO, 2001).

Ainda para Vilar Filho (2001), em 1908 foi criada a Inspetoria de Obras Contra as Secas (IOCS, que passou a se chamar IFOCS e, depois, DNOCS), primeira instituição cujo objetivo era cuidar das secas do Nordeste. Nesse período, o Nordeste sofreu a seca isolada de 1915, que ficou conhecida no Sertão do Cariri, na Paraíba, como "fome de 15", pois a seca agravara os problemas encontrados nos anos de 1913 e 1914, quando toda a lavoura temporária foi perdida devido ao excesso de água que atingiu a região naquele período.

A IOCS sofreu com a escassez de verbas nos seus 10 anos de existência, o que impedia o plano de ações daquele órgão. Essa situação motivou a apresentação de uma proposta para a criação de um fundo de irrigação para financiar obras no Nordeste (SILVA, 2006).

Já sob a denominação de Inspetoria Federal de Obras Contra as Secas (IFOCS, denominação alterada por meio do Decreto $n^{\circ}$ 13.687, de 1919), a seca, mais uma vez, castigava o Nordeste, dessa vez no ano de 1919. A instituição, que até então nada fizera, foi ativada (VILAR FILHO, 2001).

Vilar Filho (2001) ainda destaca a seca de 42/43. Ela motivou, em 1949, pelo DNOCS, a criação do fundo especial das secas, que reservava 3\% da renda tributária da União para a realização de obras no semiárido. Sobre a utilização do fundo, que apresentava novas prioridades, Silva (2006, p. 52) afirma: “[...] deveria destinar um quinto da verba para socorro às populações atingidas pela seca (obras de 
emergência e serviços de assistência) e o restante para empréstimo aos produtores rurais".

Em 1958, ano da segunda grande seca dos anos 1950 (a primeira foi em 1952), foi criado o Grupo de Trabalho para o Desenvolvimento do Nordeste (GTDN), responsável por diagnosticar a realidade e propor políticas públicas (SILVA, 2006). De acordo com Campelo e Hamasaki (2011), até1959 o DNOCS era o principal órgão governamental a executar obras, principalmente de infraestrutura. A criação da Superintendência de Desenvolvimento do Nordeste (Sudene), responsável pelo desenvolvimento regional e por seu planejamento, nos seus primeiros dias, fez surgir uma forte divergência com o DNOCS, causando prejuízos entre as instituições e o Nordeste. Campelo e Hamasaki (2011, p. 16) ainda destacam:

\begin{abstract}
Foram feitas diversas críticas ao modelo a partir dos anos 70 devido ao paternalismo e à inadequação da escolha da clientela a que se destinavam os perímetros irrigados. Porém o cenário criado não teve suas origens no Departamento, e sim, no Grupo Executivo de Irrigação e Desenvolvimento Agrário (GEIDA) criado em 1968 pelo Ministério do Interior, e era responsável pela formulação das políticas. A SUDENE ficava responsável pela supervisão e coordenação e a SUVALE (hoje CODEVASF), DNOCS e DNOS, pela execução, operação e manutenção dos projetos.
\end{abstract}

Nesse período, difundida internacionalmente, a revolução verde ${ }^{4}$ acabou substituindo, por meio de um pacote tecnológico, as formas tradicionais e locais de agricultura. Embora pregasse um aumento do nível de produção e renda por unidade de área e capital empregado, havia grande discussão sobre o futuro da agricultura brasileira, dados os resultados sociais e, sobretudo, ambientais (PÁDUA, 2004).

Em 1970, ano da seca isolada, que também fez parte do ciclo da seca, a Sudene enfraqueceu-se quando passou a ser subordinada ao Ministério do Planejamento, deixando de fazer planos trienais de desenvolvimento. Nesse período, foi criado o PIN/Proterra, que exauriu ainda mais a Sudene (BATISTA FILHO, 2001 apud CAMPELO; HAMASAKI, 2011).

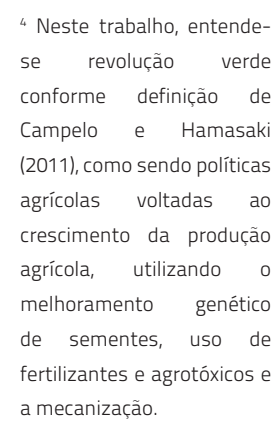


Mas, antes disso, a partir de 1964, já visando essa modernização agrícola, os gestores de políticas públicas procuraram criar uma nova estrutura institucional para a política agrícola brasileira. Nessa perspectiva, destacam-se: o Sistema Nacional de Crédito Rural (SNCR), que proporcionava aos agricultores linhas de crédito acessiveis e baratas, sendo a principal linha de crédito entre as décadas de 70 e 80; as Políticas de Garantia de Preço Mínimo (PGPM), que garantiam um preço mínimo de venda para os produtores e eram realizadas por meio do programa Aquisição do Governo Federal (AGF) e Empréstimo do Governo Federal (EGF). O primeiro eram compras feitas pelo governo federal de produtos com preço prefixados e o segundo era uma linha de crédito especial de comercialização, que tinha o propósito de financiar a estocagem (GREMAUD; VASCONCELLOS; TONETO JÚNIOR, 2009).

Ao longo dos anos 70 e 80, diversos programas e projetos de governo foram implantados com foco na agricultura familiar e no ambiente semiárido. O que se percebe é que, na medida em que os anos avançavam, mudavam-se também os objetivos e as características dos programas e projetos. O Quadro 1 apresenta 12 programas e projetos que foram lançados pelo governo federal, a partir da década de 70.

\section{Quadro 1. Programas especiais de desenvolvimento com incidência no semiárido (anos 1970 e 1980)}

\begin{tabular}{|l|l|l|}
\hline Ano & Programa/Projeto & Objetivo e características \\
\hline 1971 & PIN/Proterra & $\begin{array}{l}\text { Promover a colonização na Amazônia e no } \\
\text { Nordeste }\end{array}$ \\
\hline 1971 & Provale & Incentivo à irrigação no Vale do São Francisco \\
\hline 1974 & Polonordeste & $\begin{array}{l}\text { Apoiar polos de desenvolvimento integrado } \\
\text { no Nordeste }\end{array}$ \\
\hline 1974 & Pdan & $\begin{array}{l}\text { Programa ligado ao Polonordeste com o } \\
\text { objetivo de desenvolver a agroindústria no } \\
\text { Nordeste }\end{array}$ \\
\hline 1976 & Projeto Sertanejo & $\begin{array}{l}\text { Apoiar pequenos e médios produtores rurais } \\
\text { no Nordeste }\end{array}$ \\
\hline 1979 & Prohidro & $\begin{array}{l}\text { Fornecer água para atividades agrícolas } \\
\text { irrigadas }\end{array}$ \\
\hline 1981 & Provárzeas & $\begin{array}{l}\text { Apoiar a produção de alimentos básicos em } \\
\text { áreas de várzeas }\end{array}$ \\
\hline
\end{tabular}




\begin{tabular}{|c|c|c|}
\hline Ano & Programa/Projeto & Objetivo e características \\
\hline 1983 & Projeto Nordeste & $\begin{array}{l}\text { Reestruturar e integrar os projetos de } \\
\text { desenvolvimento do Nordeste }\end{array}$ \\
\hline 1983 & Papp & $\begin{array}{l}\text { Apoiar o pequeno produtor rural por meio } \\
\text { de infraestrutura, irrigação, crédito rural, } \\
\text { comercialização, assistência técnica e } \\
\text { extensão, pesquisa e acesso à terra }\end{array}$ \\
\hline 1986 & Projeto São Vicente & $\begin{array}{l}\text { Oferecer suporte técnico e financeiro a } \\
\text { pequenos produtores rurais nordestinos }\end{array}$ \\
\hline 1986 & Proine & Promover a irrigação no Nordeste \\
\hline 1988 & Projeto Padre Cícero & $\begin{array}{l}\text { Ampliar o número de reservatórios de água } \\
\text { no interior do Nordeste, incentivando a } \\
\text { convivência com a seca }\end{array}$ \\
\hline
\end{tabular}

Fonte: Andrade (1984 apud SILVA 2006); BURSZTYN (1985 apud SILVA 2006); CARVALHO (1988 apud SILVA 2006); VILLA (2000 apud SILVA 2006).

Segundo Campelo e Hamasaki (2011), no final dos anos 70, as principais políticas de combate à seca esgotaram-se com o fim da revolução verde. Embora na agricultura ainda existam práticas acentuadas de um modelo produtivista brutal, como o uso de agrotóxicos, sementes modificadas e fertilizantes químicos, a revolução verde, como um paradigma ideológico, sustentado pelas políticas públicas voltadas para a agricultura familiar, que implantava esses pacotes tecnológicos, está praticamente extinta. A partir daí, é importante observar mais atentamente as políticas públicas mais atuais de convivência com o semiárido, que acompanharam a transição dos métodos convencionais de produção para a agroecologia.

Nas linhas seguintes, tenta-se resgatar os principais fatores que marcaram a transformação da agricultura familiar, observando paralelamente as políticas públicas de convivência com o semiárido, entendendo a relação dessas políticas com a mudança das antigas práticas convencionais de produção para a agroecologia.

\section{A transformação da agricultura familiar e as políticas de convivência com o semiárido}

Na metade do século $X X$, houve um aumento significativo da população urbana do Brasil. Assim, o País sofreu um processo de 
“desruralização". No contexto histórico do País, nesse período, houve um crescimento, além da população urbana, da industrialização, o que supõe uma estrutura agrária concentrada e desigual (PÁDUA, 2004).

A transformação da agricultura familiar, aliada a uma nova perspectiva de desenvolvimento rural, tomou força a partir da década de 70. Foi nas três últimas décadas antes do século XX que se podem perceber as grandes mudanças na agricultura familiar e, consequentemente, nas políticas públicas direcionadas para essa atividade.

De acordo com Jalfim (2011), a lógica do desenvolvimento preconizado pelo Estado, baseada no combate à seca, perdurou por centenas de anos. Mais do que a lógica equivocada sobre a ecologia, trazia no seu bojo uma perversa forma de dominação social e política das oligarquias. Ainda de acordo com o autor (Ibidem, p. 72):

Essa dominação era alicerçada na dependência socioeconômica das famílias agricultoras através do tripé: concentração fundiária; precário acesso à água, notadamente relacionado à solução hidráulica, que não atendiam à demanda difusa por água; e políticas públicas clientelistas, simbolizadas pelo uso do caminhão-pipa.

Assim, a agroecologia surgia como um novo paradigma na agricultura familiar. Muito embora o agronegócio estivesse fortemente presente na agricultura familiar, a agroecologia provocava uma verdadeira mudança na agricultura de base familiar, assim como afirma Pádua (2004, p. 212):

Para implementar este paradigma, que tem sido chamado de agroecologia, a agricultura familiar vem sendo revalorizada e reconhecida por muitos especialistas como um espaço privilegiado. Essa aposta é, em primeiro lugar, conceitual. A ideia básica é de que a agroecologia não pode ser implementada a partir de pacotes tecnológicos, requerendo, ao contrário, um tratamento específico no contexto de cada propriedade.

Sobre este novo modelo, Diniz e Piraux (2011) afirmam que é justamente a partir dos anos de 1970 que começa o movimento de modernização agrícola em grande escala, dirigido especialmente pelo 
Estado. IssoreforçasobremaneiraqueoEstadonãosóacompanhouessa transformação; foi muito além. Ele foi responsável pelo fortalecimento da agricultura familiar e estimulador do desenvolvimento rural.

Para Jalfim (2011), uma convergência entre iniciativas nacionais, a partir da década de 80, como o Projeto de Tecnologias Alternativas (PTA), tentava romper com o modelo de combate à seca, dando início a uma longa caminhada capaz de substituir a velha política por um modelo que integrasse as dimensões ecológicas, técnicas, culturais e socioeconômicas.

Nessa perspectiva, a Articulação no Semiárido Brasileiro (ASA) desenvolveu algumas tecnologias sociais ${ }^{5}$ que são simples, baratas e de domínio de agricultores e agricultoras. Inicialmente, em 2003, a ASA implantou o Programa Um Milhão de Cisternas (P1MC), cujo objetivo era beneficiar cerca de cinco milhões de pessoas em toda a região semiárida com água potável para beber e cozinhar, por meio das cisternas de placas. Hoje, a ASA conta com mais sete tecnologias sociais, por meio do Programa Uma Terra e Duas Águas (P1+2), desenvolvidas especialmente para captar água para a produção de alimentos: cisterna-calçadão, cisterna-enxurrada, barragem subterrânea, barreiro trincheira, barraginha, tanque de pedra e bomba d'água popular (ASA, 2013).

Quanto às políticas públicas voltadas para a agricultura familiar em clima semiárido, Campelo e Hamasaki (2011, p. 3) afirmam:

[...] devido a grandes períodos de estiagens e seca, aumentam as dificuldades de produção. Para o agricultor familiar poder produzir nessa região, é necessária uma política pública de fomento, seja por parte do governo, seja por parte de uma ONG (Organização NãoGovernamental), ou seja, é preciso colocar em prática uma Assessoria Técnica Permanente, de ação contínua e holística, focada na demanda, objetivo e interesse das famílias; e ainda, apoiar a agricultura familiar para promoção da segurança hídrica e alimentar; apoiar a produção e comercialização; possibilitar aos agricultores familiares acesso aos mercados locais, institucionais, justo e orgânico, como meio de agregar valor à produção e aumentar a renda dos agricultores familiares.
${ }^{5}$ Segundo a Rede de Tecnologias Sociais (RTS), do Ministério da Ciência, Tecnologia e Inovação, a tecnologia social é o conjunto de atividades relacionadas a estudos, planejamento, ensino, pesquisa, extensão e desenvolvimento de produtos, técnicas ou metodologias reaplicáveis, que representem soluções para o desenvolvimento social e melhoria das condições de vida da população. 
É nessa perspectiva que se destacam as principais políticas públicas atuais, do governo federal, de apoio à agricultura familiar, alicerçadas na ideologia de convivência com o clima semiárido. Incialmente, pode-se destacar a Política de Assistência Técnica e Extensão Rural para a Agricultura Familiar e Reforma Agrária (Pnater).

Dadas as carências particulares da agricultura familiar, a Pnater, instituída com a Lei $n^{\circ}$ 12.188, de 11 de janeiro de 2010, veio valorizar a lógica de produção e reprodução social, suas dinâmicas e experiências, conforme seus objetivos, principalmente aqueles intrinsecamente relacionados com um modelo de agricultura sustentável (BRITO, 2011).

Ainda para Brito (2011 apud BRASIL 2010, p. 23), sobre os investimentos voltados para a agricultura familiar:

[...] as iniciativas são melhor traduzidas em números quando se verifica que, de 2003 a 2009, o investimento em Assistência Técnica e Extensão Rural (ATER) para a AF subiu de $\mathrm{R} \$ 46$ milhões para $\mathrm{R} \$ 428$ milhões ao ano, que, somados com o apoio aos assentados da reforma agrária, o valor chega a $\mathrm{R} \$ 626$ milhões só na safra 2009/2010, com um total de 24 mil técnicos).

Além da Pnater, merece grande destaque o Programa Nacional de Fortalecimento da Agricultura Familiar (Pronaf). Esse programa oferece diversas linhas de crédito para o agricultor familiar. Segundo a Secretaria da Agricultura Familiar (BRASIL, 2012):

O Programa Nacional de Fortalecimento da Agricultura Familiar (Pronaf) financia projetos individuais ou coletivos, que gerem renda aos agricultores familiares e assentados da reforma agrária. O programa possui as mais baixas taxas de juros dos financiamentos rurais, além das menores taxas de inadimplência entre os sistemas de crédito do País.

Os agentes financeiros que operam o Pronaf compõem o Sistema Nacional de Crédito Rural (SNCR), que, conforme apresentado anteriormente, era principal linha de crédito nas décadas de 70 e 80, e são agrupados em básicos (Banco do Brasil, Banco do Nordeste e Banco da Amazônia) e vinculados (BNDES, Bancoob, Bansicredi e associados à Febraban). 
De acordo com Denardi (2001), o Pronaf proporcionou uma política pública diferenciada para a agricultura familiar. No entanto, o Pronaf é um campo de disputa de duas forças. De um lado, o Ministério do Desenvolvimento Agrário, que vê o programa como uma efetiva política de desenvolvimento rural; do outro, os ministérios da Fazenda e da Agricultura, Pecuária e Abastecimento, que veem o Pronaf apenas como uma política social compensatória.

Segundo o Instituto de Pesquisa Econômica Aplicada (IPEA, 2012), houve um grande avanço no montante de crédito aplicado pelo Pronaf, beneficiando diretamente a agricultura familiar. No ano agrícola de 1998/1999, houve um montante de crédito rural na ordem de $\mathrm{R} \$$ $1.263 .133 .634,16$, realizados por meio de 174.286 contratos. Passados 12 anos, no ano agrícola de 2010/2011, o montante aplicado foi 809,2\% superior, quando comparado com o ano agrícola de 1998/1999, atingindo um montante de $\mathrm{R} \$ 11.484 .067 .137,86$.

De acordo com o Ministério do Desenvolvimento Agrário (BRASIL, 2013), o valor destinado ao crédito rural é recorde. Segundo o Plano Safra, apresentado pelo MDA para o ano agrícola de 2012/2013, os agricultores e as agricultoras terão à disposição $\mathrm{R} \$ 18$ bilhões para as linhas de custeio, investimento e comercialização do Pronaf.

Nesse sentido, o que tem se visto é um aumento crescente do acesso ao crédito, porém, o reflexo disso de forma qualitativa ainda é muito baixo. Para atender a esse aumento e facilitar o acesso ao crédito, o Pronaf trabalha com algumas linhas de créditos divididas por categorias, conforme se apresenta a seguir:

\section{Quadro 2. Linhas de crédito do Pronaf}

\begin{tabular}{|l|l|}
\hline Linhas de Crédito & Descrição \\
\hline Custeio & $\begin{array}{l}\text { Destina-se ao financiamento das atividades } \\
\text { agropecuárias e de beneficiamento ou industrialização } \\
\text { e comercialização de produção própria ou de terceiros } \\
\text { agricultores familiares enquadrados no Pronaf. }\end{array}$ \\
\hline Investimento & $\begin{array}{l}\text { Destinado ao financiamento da implantação, ampliação } \\
\text { ou modernização da infraestrutura de produção e } \\
\text { serviços, agropecuários ou não agropecuários, no } \\
\text { estabelecimento rural ou em áreas comunitárias rurais } \\
\text { próximas. }\end{array}$ \\
\hline
\end{tabular}




\begin{tabular}{|c|c|}
\hline Linhas de Crédito & Descrição \\
\hline $\begin{array}{l}\text { Pronaf } \\
\text { Agroindústria }\end{array}$ & $\begin{array}{l}\text { Linha para o financiamento de investimentos, inclusive } \\
\text { em infraestrutura, que visam o beneficiamento, o } \\
\text { processamento e a comercialização da produção } \\
\text { agropecuária e não agropecuária de produtos florestais } \\
\text { e do extrativismo ou de produtos artesanais, além da } \\
\text { exploração de turismo rural. }\end{array}$ \\
\hline $\begin{array}{l}\text { Pronaf } \\
\text { Agroecologia }\end{array}$ & $\begin{array}{l}\text { Linha para o financiamento de investimentos dos } \\
\text { sistemas de produção agroecológicos ou orgânicos, } \\
\text { incluindo-se os custos relativos à implantação e } \\
\text { manutenção do empreendimento. }\end{array}$ \\
\hline Pronaf Eco & $\begin{array}{l}\text { Linha para o financiamento de investimentos em } \\
\text { técnicas que minimizem o impacto da atividade rural } \\
\text { no meio ambiente, bem como permitam ao agricultor } \\
\text { melhor convívio com o bioma em que sua propriedade } \\
\text { está inserida. }\end{array}$ \\
\hline Pronaf Floresta & $\begin{array}{l}\text { Financiamento de investimentos em projetos para } \\
\text { sistemas agroflorestais; exploração extrativista } \\
\text { ecologicamente sustentável; plano de manejo florestal; } \\
\text { recomposição e manutenção de áreas de preservação } \\
\text { permanente; e reserva legal e recuperação de áreas } \\
\text { degradadas. }\end{array}$ \\
\hline Pronaf Semiárido & $\begin{array}{l}\text { Linha para o financiamento de investimentos em } \\
\text { projetos de convivência com o semiárido, focados } \\
\text { na sustentabilidade dos agroecossistemas, } \\
\text { priorizando infraestrutura hídrica e implantação, } \\
\text { ampliação, recuperação ou modernização das demais } \\
\text { infraestruturas, inclusive daquelas relacionadas com } \\
\text { projetos de produção e serviços agropecuários e não } \\
\text { agropecuários, de acordo com a realidade das famílias } \\
\text { agricultoras da região semiárida. }\end{array}$ \\
\hline Pronaf Mulher & $\begin{array}{l}\text { Linha para o financiamento de investimentos de } \\
\text { propostas de crédito da mulher agricultora. }\end{array}$ \\
\hline Pronaf Jovem & $\begin{array}{l}\text { Financiamento de investimentos de propostas de } \\
\text { crédito de jovens agricultores e agricultoras. }\end{array}$ \\
\hline $\begin{array}{l}\text { Pronaf Custeio e } \\
\text { Comercialização } \\
\text { de Agroindústrias } \\
\text { Familiares }\end{array}$ & $\begin{array}{l}\text { Destinada aos agricultores e suas cooperativas ou } \\
\text { associações para que financiem as necessidades de } \\
\text { custeio do beneficiamento e da industrialização da } \\
\text { produção própria e/ou de terceiros. }\end{array}$ \\
\hline $\begin{array}{l}\text { Pronaf Cota- } \\
\text { Parte }\end{array}$ & $\begin{array}{l}\text { Financiamento de investimentos para a integralização } \\
\text { de cotas-partes dos agricultores familiares filiados } \\
\text { a cooperativas de produção ou para a aplicação em } \\
\text { capital de giro, custeio ou investimento. }\end{array}$ \\
\hline
\end{tabular}




\begin{tabular}{|l|l|}
\hline Linhas de Crédito & Descrição \\
\hline Microcrédito & $\begin{array}{l}\text { Destinado aos agricultores de mais baixa renda, } \\
\text { permite o financiamento das atividades agropecuárias } \\
\text { e não agropecuárias, podendo os créditos cobrir } \\
\text { qualquer demanda que possa gerar renda para a } \\
\text { família atendida. Crédito para agricultores familiares } \\
\text { enquadrados no Grupo B e agricultoras integrantes } \\
\text { das unidades familiares de produção enquadradas nos } \\
\text { Grupos A ou A/C. }\end{array}$ \\
\hline $\begin{array}{l}\text { Pronaf Mais } \\
\text { Alimentos }\end{array}$ & $\begin{array}{l}\text { Financiamento de propostas ou projetos de } \\
\text { investimento para a produção associados a açafrão, } \\
\text { arroz, café, centeio, feijão, mandioca, milho, sorgo, } \\
\text { trigo, erva-mate, apicultura, aquicultura, avicultura, } \\
\text { bovinocultura de corte, bovinocultura de leite, } \\
\text { caprinocultura, fruticultura, olericultura, ovinocultura, } \\
\text { pesca e suinocultura. }\end{array}$ \\
\hline
\end{tabular}

Fonte: Secretaria da Agricultura Familiar (BRASIL, 2012).

Ao longo das últimas três décadas, houve um crescimento sustentado por meio da contratação de créditos do Pronaf. Esse crescimento foi percebido não apenas pelo volume de recursos contratados, como também pelo número de beneficiários que acessaram o crédito. De acordo com a própria Secretaria da Agricultura Familiar, em 1999/2000, o Pronaf abrangia 3.403 municípios, passando para 5.379 em 2007/2008, um crescimento de 58\% em relação a 1999/2000.

Além da Pnater e do Pronaf, destaca-se também o Programa de Aquisição de Alimentos (PAA), outra grande política pública direcionada para a agricultura familiar, cuja ideologia está alicerçada na estratégia de convivência com o semiárido.

Segundo a Secretaria de Agricultura Familiar, o PAA foi criado em 2003 e seu objetivo principal é colaborar com o enfrentamento da fome e da pobreza no Brasil; ao mesmo tempo, fortalecer a agricultura familiar. Para tanto, o governo federal utiliza mecanismos que favorecem a aquisição direta de produtos de agricultores familiares ou de suas organizações, estimulando os processos de agregação de valor à produção. 
De acordo com o Ministério do Desenvolvimento Agrário (BRASIL, 2010), de 2003 a 2009, o PAA beneficiou 764 mil famílias de agricultores, gerando uma renda média anual, por família, de $\mathrm{R} \$ 3,9$ mil. Nesse período, as compras do PAA totalizaram um montante de $\mathrm{R} \$ 2,7$ bilhões. Para tanto, foram adquiridos 2,5 milhões de toneladas de alimentos, beneficiando 7,5 milhões de consumidores por ano.

O PAA vai muito além do que simplesmente viabilizar a comercialização dos alimentos. O programa representa uma garantia de mercado para a agricultura familiar, e, nesse contexto, o governo federal apresenta duas importantes preocupações: enfrentar o problema social e promover a inclusão social no meio rural, fortalecendo a principal atividade econômica.

Para ir além da ponte entre a produção e o combate à fome, o governo federal realiza a aquisição de alimentos, conforme as modalidades apresentadas no Quadro 3:

\section{Quadro 3. Modalidade dos PAA}

\begin{tabular}{|l|l|}
\hline Modalidade & Ação \\
\hline $\begin{array}{l}\text { Compra direta da } \\
\text { agricultura familiar }\end{array}$ & $\begin{array}{l}\text { Voltada à aquisição de produtos em situação de baixa } \\
\text { de preço ou em função da necessidade de atender às } \\
\text { demandas de alimentos de populações em condições } \\
\text { de insegurança alimentar. }\end{array}$ \\
\hline $\begin{array}{l}\text { Apoio à formação } \\
\text { de estoques pela } \\
\text { agricultura familiar }\end{array}$ & $\begin{array}{l}\text { Disponibiliza recursos para que as organizações da } \\
\text { agricultura familiar somem estoques de produtos } \\
\text { condições de mercado. }\end{array}$ \\
\hline $\begin{array}{l}\text { Compra com } \\
\text { doação simultânea } \\
\text { ou compra direta } \\
\text { local }\end{array}$ & $\begin{array}{l}\text { Responsável pela doação de produtos adquiridos } \\
\text { da agricultura familiar a pessoas em situação de } \\
\text { insegurança alimentar e nutricional. }\end{array}$ \\
\hline PAA Leite & $\begin{array}{l}\text { Assegura a distribuição gratuita de leite em ações } \\
\text { de combate à fome e à desnutrição de cidadãos que } \\
\text { estejam em situação de vulnerabilidade social ou } \\
\text { em estado de insegurança alimentar e nutricional. } \\
\text { Atende aos estados do Nordeste. }\end{array}$ \\
\hline
\end{tabular}

Fonte: Ministério do Desenvolvimento Agrário (BRASIL, 2010). Modificado pelo autor. 
O governo federal apresenta ainda outros programas voltados para a agricultura familiar, como o Programa Nacional do Biodiesel, que incentiva as unidades produtoras de biodiesel. No ano de 2008, a indústria comprou $\mathrm{R} \$ 230$ milhões em oleaginosas da agricultura familiar, passando para R\$600 milhões em 2009 (BRASIL, 2010).

Outro importante programa é o Seguro da Agricultura Familiar (Seaf), que, segundo o Ministério do Desenvolvimento Agrário (BRASIL, 2010), amparou 500 mil famílias. O seguro é ativado toda vez que houver perda maior que $30 \%$ da lavoura ou a receita for menor do que $70 \%$ da receita esperada.

Todos esses programas realizados pelo governo federal ratificam a força da agricultura familiar e a importância de atender às demandas desses produtores. A transformação da agricultura e sua modernização requereram dos gestores políticas públicas mais dinâmicas que atendessem às diferentes necessidades sazonais e regionais.

\section{Considerações finais}

Todas essas políticas acompanharam a transformação da agricultura familiar no Brasil. Percebe-se que ainda não há uma estratégia que seja um modelo para solucionar o problema da agricultura familiar. O que se tem é que as políticas continuam acompanhando as mudanças e as diferentes demandas da agricultura familiar; além disso, estão consoante as demais políticas sociais, fundamentalmente de combate à pobreza extrema e à dinâmica da economia nacional.

Assim, a participação do Estado na promoção do desenvolvimento sustentável da agricultura familiar, por meio de políticas de fomento à população rural, mostra-se essencial. Não há como pensar no desenvolvimento da agricultura familiar sem a intervenção do Estado, tendo em vista toda a carência da região e os limites impostos pelo clima. 
Do combate à seca à convivência com o clima semiárido, mostra que as ideologias, baseadas em estratégias de governo, vão se modificando, buscando atender à complexidade da região semiárida, às necessidades dos agricultores familiares e à própria burocracia das políticas públicas. Porém, o que se vê é uma crescente e sustentada evolução das políticas públicas para a agricultura familiar.

Recebido 01/10/2012

Aprovado 25/07/2013

\section{Referências bibliográficas}

ALTIERI, M. Agroecologia: bases científicas para uma agricultura sustentável. 3. ed. Ver. ampl. São Paulo, Rio de Janeiro: Expressão Popular, AS-PTA, 2012.

ASA - Articulação no Semiárido Brasileiro. Tecnologias Sociais. Disponivel em: <http://www.asabrasil.org.br/Portal/Informacoes. asp?COD_MENU=1151>. Acesso em: 03 jun. 2013.

BRASIL. Ministério da Integração Nacional. Relatório Final do Grupo de Trabalho Interministerial para delimitação do semi-árido nordestino e do Polígono das Secas. Brasília: 2005. Disponível em: <http://www. cpatsa.embrapa.br/public_eletronica/downloads/OPB1839.pdf $>$. Acesso em: 03 jun. 2013.

Ministério do Desenvolvimento Agrário. Um novo Brasil rural. Brasília, DF: 2010. Disponível em: <http://portal.mda.gov.br/portal/ publicacoes/download_orig_file?pageflip_id=4405346>. Acesso em: 03 jun. 2013.

Secretaria de Agricultura Familiar. Crédito Rural. Disponivel em < http://www.mda.gov.br/portal/saf/programas/pronaf>. Acesso em: 25 jul. 2012.

Ministério do Desenvolvimento Agrário. R\$ 22,3 bilhões para

o fortalecimento da Agricultura Familiar Safra 2012/2013. Disponivel 
em: <http://www.mda.gov.br/plano-safra/xowiki/recursos>. Acesso em: 04 jun. 2013.

BRITO, J. A. G. de. Agricultura familiar e sustentável: um estudo de caso da Associação Vanguarda, do Município de Cabo de Santo Agostinho. 2011. Dissertação (Mestrado em Gestão do Desenvolvimento Local Sustentável)- Faculdade de Ciências da Administração de Pernambuco, Universidade de Pernambuco, Recife.

CAMPELO, D. A.; HAMASAKI, C.S. Políticas públicas e ações sustentáveis no semiárido pernambucano: fortalecimento da pequena agricultura familiar. Revista da Ciência da Administração, v. 4, p. 1-34, dez. 2011.

DENARDI, R. A. Agricultura familiar e políticas públicas: alguns dilemas e desafios para o desenvolvimento rural sustentável. Agroecologia e Desenvolvimento Rural Sustentável, Porto Alegre, v. 2, n. 3, jul./set. 2001.

DINIZ, P. C. O.; PIRAUX, M. Agroecologia e convivência com semiárido: breves notas de uma longa trajetória de diálogos e interfaces. In: LIMA, J. R. T. de (Org.). Agroecologia e Movimentos Sociais. Recife: Editora Bagaço, 2011.

FAO/INCRA. Novo Retrato da Agricultura Familiar - O Brasil Redescoberto. Brasília: Projeto de Cooperação Técnica, 2000.

GLIESSMAN, S. R. Agroecologia: processos ecológicos em agricultura sustentável. Porto Alegre: Ed. Universidade/UFRGS, 2000.

GREMAUD, A. P.; VASCONCELLOS, M. A. S.; TONETO JÚNIOR, R. Economia Brasileira Contemporânea. São Paulo: Atlas, 2009.

IBGE-Instituto Brasileiro de Geografia e Estatística. Censo Agropecuário 2006. ISSN 0103-6157. Rio de Janeiro: IBGE, 2006.

IPEA - Instituto de Pesquisa Econômica Aplicada. Políticas sociais: acompanhamento e análise. 20. ed. Brasília: Ipea, 2012. 
JALFIM, F. Notas sobre a caminhada da agroecologia no semiárido pernambucano. In: LIMA, J. R. T. de (Org.). Agroecologia e Movimentos Sociais. Recife: Editora Bagaço, 2011.

MOURA, A. Contribuições do SERTA para a Agroecologia no Estado de Pernambuco. In: LIMA, J. R. T. de (Org.). Agroecologia e Movimentos Sociais. Recife: Editora Bagaço, 2011.

MOURA, S. A gestão do desenvolvimento local: estratégias e possibilidades de financiamento. Organizações \& Sociedade, Salvador, v. 5, n. 12, maio/ago. 1998.

PÁDUA, J. A. Agricultura Sustentável. In: CAMARGO, A.; CAPOBIANCO, J. P. R.; OLIVEIRA, J. A. P. de. (Orgs.). Meio ambiente Brasil: avanços e obstáculos pós Rio-92. 2. ed. São Paulo: FGV, Instituto Socioambiental e Estação Liberdade, 2004. p. 200-219. Parte II.

SANTOS, T. dos. Em busca de uma nova aliança política para o desenvolvimento. In: MARTINS, P. E. M.; PIERANTI, O. P. (Orgs.). Estado e Gestão Pública: visões do Brasil contemporâneo. Reimpressão. São Paulo: Editora FGV, 2007.

SILVA, R. M. A. da. Entre o combate à seca e a convivência com - semiárido: transições paradigmáticas e sustentabilidade do desenvolvimento. 2006. Tese (Doutorado em Desenvolvimento Sustentável)- Centro de Desenvolvimento Sustentável, Universidade de Brasília, Brasília. 298 p.

TEIXEIRA, E. C. O papel das políticas públicas no desenvolvimento local e na transformação da realidade. Salvador, Bahia: AATR, 2002.

TOLEDO, E. de la G. Neoliberalismo e Estado. In: LAURELL, A. C. (Org.). Estado e Políticas Sociais no Neoliberalismo. Trad. Rodrigo Leon Contrera. 3. ed. São Paulo: Cortez, 2002.

VILAR FILHO, M. D. Secas e Ciclos - Sinopse Analítica. In: FILHO, M. B. (Org.). Viabilização do Semi-Árido do Nordeste. Recife: Imip, 2011. p. $52-58$. 